\title{
Reação de Cultivares de Batata à Podridão Mole Causada por Pectobacterium carotovorum subsp. atrosepticum, por P. carotovorum subsp. carotovorum e por $P$. chrysanthemi*
}

\author{
Adilce I. H. Benelli ${ }^{1 * *}$, Norimar D. Denardin ${ }^{1}$, Carlos A. Forcelini ${ }^{1}$ \& Valmir Duarte ${ }^{2}$
}

${ }^{1}$ Faculdade de Agronomia e Medicina Veterinária, Universidade de Passo Fundo, Cx. Postal 611, CEP 99001-970 Passo Fundo, RS, Fax: (054) 316 8152, e-mail: norimar@upf.tche.br; ${ }^{2}$ Departamento de Fitossanidade, Faculdade de Agronomia,

Universidade Federal do Rio Grande do Sul, Cx. Postal 776, CEP 91540-000 Porto Alegre, RS, Fax (051) 3163121

(Aceito para publicação em 17/11/2003)

Autor para correspondência: Norimar D'Ávila Denardin

BENELLI, A.I.H., DENARDIN, N.D., FORCELINI, C.A. \& DUARTE, V. Reação de cultivares de batata à podridão mole causada por Pectobacterium carotovorum subsp. atrosepticum, por P. carotovorum subsp. carotovorum e por P. chrysanthemi. Fitopatologia Brasileira 29:155-159. 2004.

\section{RESUMO}

A podridão mole em tubérculos de batata (Solanum tuberosum), causada por Pectobacterium carotovorum subsp. atrosepticum, por Pectobacterium carotovorum subsp. carotovorum e por $P$. chrysanthemi, é uma preocupante doença que causa danos expressivos à cultura em todo o mundo. Como inexiste tratamento eficiente para a podridão mole, o desenvolvimento de cultivares resistentes é considerado o método mais eficaz para a redução de perdas causadas pela doença. Nesse sentido, quatro cultivares de batata foram avaliados quanto à resistência natural às pectobactérias, mediante redução de massa de tubérculos após 20,
24, 48, 72 e 96 h de inoculação com suspensões bacterianas. O delineamento experimental constou de um esquema fatorial com quatro cultivares, três bactérias e quatro repetições. Os resultados foram transformados em proporção e integralizados como área abaixo da curva de progresso da doença (AACPD). Para as três bactérias estudadas, a cultivar Asterix mostrou-se o menos suscetível à podridão mole, diferindo significativamente dos demais.

Palavras-chave adicionais: Solanum tuberosum, Pectobacterium, resistência.

\section{ABSTRACT}

Reaction of potato cultivars to soft rot caused by Pectobacterium carotovorum subsp. atrosepticum, P. carotovorum subsp. carotovorum and $P$. chrysanthemi

Soft rot caused by Pectobacterium carotovorum subsp. atrosepticum, Pectobacterium carotovorum subsp. carotovorum and P. chrysanthemi is a severe disease of potato (Solanum tuberosum) worldwide. Since there is no efficient treatment for soft rot, the use of resistant cultivars is considered the most effective method to reduce crop losses due to this disease. In this research, four potato cultivars were evaluated regarding their resistance to pectobacteria. Tubers inoculated with bacterial suspensions were assessed for mass reduction at five periods $(20,24,48,72$, and $96 \mathrm{~h})$ after inoculation. The experimental design consisted of a factorial scheme with four cultivars, three bacteria, and four replications. The data on tuber mass loss were transformed into proportion and integrated as the area under the disease progress curve. For all three bacteria, the cultivar Asterix was the less susceptible to soft rot and differed significantly from the others.

\section{INTRODUÇÃO}

Dentre os estados brasileiros maiores produtores de batata (Solanum tuberosum L.)- São Paulo, Minas Gerais, Paraná, Santa Catarina e Rio Grande do Sul -, este último ocupa o primeiro lugar em área plantada (39.377 ha), porém o quinto em produtividade, em torno de 9,8 $\mathrm{t} \mathrm{ha}^{-1}$ (Sidra-IBGE, 2001). Essa baixa produtividade resulta, em grande parte, da carência de cultivares adaptadas às condições climáticas e resistentes às doenças típicas da região (Bisognin, 1996). Nesse sentido, este estudo propôs-se a avaliar a reação das cultivares Achat, Asterix, Baronesa e Monalisa, amplamente cultivadas no Estado do Rio Grande do Sul, às bactérias incitantes de podridão mole.

\footnotetext{
*Parte da Dissertação de Mestrado do primeiro autor. Universidade de Passo Fundo (2002).

** Bolsista da CAPES
}

Perdas significativas de até $100 \%$ durante a estocagem de tubérculos de batata são atribuídas a podridões causadas por bactérias do gênero Pectobacterium (Elphistone, 1987; Lapwood \& Gans, 1984), especificamente Pectobacterium carotovorum subsp. atrosepticum (van Hall, 1902) Hauben et al., 1998, P. carotovorum subsp. carotovorum (Jones, 1901) Hauben et al., 1998 e P. chrysanthemi (Bulkholder et al., 1953) Hauben et al., 1998.

Pectobacterium carotovorum subsp. atrosepticum (Pca) tem ocorrência mais restrita a regiões de clima temperado, onde a cultura de batata tem se desenvolvida extensivamente (Pérombelon \& Kelman, 1987). A subspécie P. carotovorum subsp. carotovorum (Pcc) possui ampla distribuição nas zonas temperada e tropical e pode sobreviver em diversos ambientes, incluindo solos, rios e lagos (De Boer et al., 1987). Pectobacterium chrysanthemi (Pch) está distribuída em regiões 
tropicais e subtropicais e em zonas mais quentes das regiões temperadas (Cappaert et al., 1988).

O manejo da doença é afetado pela espécie ou subespécie presente, que depende diretamente da temperatura ótima de desenvolvimento: 15 a $20^{\circ} \mathrm{C}, 27$ a $30^{\circ} \mathrm{C}$ e 34 a $37^{\circ} \mathrm{C}$ para $\mathrm{Pca}$, Pcc e Pch, respectivamente (Oliveira, 2001).

Os melhores meios para controlar a doença incluem plantio de tubérculos-semente sadios, redução de injúrias nos tubérculos durante a colheita e condições adequadas de estocagem. Essas técnicas de manejo têm sido insuficientes para o controle da doença, uma vez que a bactéria pode penetrar por aberturas naturais nos tubérculos. Outros meios podem ser empregados para minimizá-la, como, por exemplo, o emprego de cultivares resistentes.

Embora as cultivares de batata variem quanto à suscetibilidade à podridão mole, poucas cultivares comumente cultivadas na América do Norte e na Europa são consideradas altamente resistentes (Lapwood et al., 1984; Pérombelon et al., 1988; Wastie et al., 1988; Tzeng et al., 1990). No Brasil não há registro de cultivares resistentes à podridão mole incitada por pectobactérias.

\section{MATERIAL E MÉTODOS}

Os experimentos foram conduzidos na Faculdade de Agronomia e Medicina Veterinária da Universidade de Passo Fundo, no período de março de 2000 a novembro de 2001.

Estirpes das bactérias Pca (424), Pcc (1131) e Pch (1383) obtidas da Coleção do Instituto Biológico de São Paulo, Estação Experimental de Campinas, SP, depois de purificadas e reidentificadas, foram preservadas em meio inclinado 523 de Kado e Heskett (Kado \& Heskett, 1970), em goma xantana (GX) a 1,0\% e em GX (1,0\%) + polivinilpirrolidona (PVP $1,5 \%$ ) (Denardin \& Freire, 2000; Tumelero \& Denardin, 2001). Nos dois últimos processos de conservação, obedeceu-se à proporção de $2: 1$, ou seja, duas partes do produto elaborado para uma de suspensão bacteriana. A conservação das estirpes, independentemente do processo de preservação, ocorreu em temperatura de $4{ }^{\circ} \mathrm{C}$.

Tubérculos de batata das cultivares Achat, Monalisa e Baronesa foram obtidos na Empresa Brasileira de Pesquisa Agropecuária (Embrapa Transferência de Tecnologia-Escritório de Negócios de Canoinhas, SC) e da cultivar Asterix da Empresa de Sementes Básicas Bocche, Ibiraiaras, RS. Após o recebimento, os tubérculos foram mantidos à temperatura de $4 \mathrm{a} 5^{\circ} \mathrm{C}$.

A avaliação do estado sanitário dos tubérculos detectou aparência saudável, pois as bactérias incitadoras da podridão mole podem estar presentes em estado de latência na superfície ou nas lenticelas dos tubérculos. Para detectá-las, amostras de tecido foram suspensas em meio líquido 523 de Kado e Heskett (Kado \& Heskett, 1970) e incubadas durante 24 h à temperatura de $28^{\circ} \mathrm{C}$ e, a seguir, essa suspensão foi semeada em meio sólido 523 de Kado e Heskett (Kado \& Heskett, 1970) e incubada a $28{ }^{\circ} \mathrm{C}$ durante $48 \mathrm{~h}$. As colônias que se desenvolveram isoladamente foram examinadas quanto às características culturais. Aquelas de coloração branca, opacas e de bordos irregulares foram transferidas para placas contendo meio sólido 523 de Kado e Heskett (Kado \& Heskett, 1970) e incubadas nas mesmas condições descritas anteriormente. Testes bioquímicos e fisiológicos determinaram o gênero das bactérias isoladas. Isolados gram-negativos, de reação oxidase negativa e anaeróbicos facultativos, com capacidade de maceração de frutos de pimentão verde, foram considerados pertencentes ao gênero Pectonbacterium do grupo carotovorum (Robbs, 1981; Schaad, 2001).

Para avaliar a reação das cultivares à podridão mole, primeiramente obteve-se o inóculo a partir de culturas bacterianas desenvolvidas em meio líquido 523 de Kado e Heskett (Kado \& Heskett, 1970) por $48 \mathrm{~h}$ à temperatura de $28^{\circ} \mathrm{C}$, diluídas em solução tampão fosfato $\left(\mathrm{K}_{2} \mathrm{HPO}_{4}, 1,13 \mathrm{~g} \mathrm{l}^{-1} ; \mathrm{KH}_{2} \mathrm{PO}_{4}, 0,48\right.$ $\mathrm{g} \mathrm{1}^{-1} ; \mathrm{pH} \mathrm{7,2).} \mathrm{Posteriormente,} \mathrm{essas} \mathrm{suspensões} \mathrm{foram} \mathrm{ajustadas}$ para densidade óptica de 0,5 de absorbância em $550 \mathrm{~nm}$ (Leilliot \& Stead, 1987) em espectrofotômetro (Spectronic? - 20 Genesys $^{\mathrm{TM}}$ ), resultando numa concentração entre $10^{8}$ e $10^{10}$ unidades formadoras de colônias (UFCs) por ml para Pca, para Pcc e para Pch.

Procedeu-se a desinfestação dos tubérculos em álcool $96{ }^{\circ} \mathrm{GL}$ durante $3 \mathrm{~min}$, seguida de imersão em solução de hipoclorito de sódio $(\mathrm{NaOCl})$ a $1 \%$ por 5 min e à lavagem por seis vezes sucessivas em água destilada e esterilizada. Decorridas $24 \mathrm{~h}$ da desinfestação, os tubérculos foram inoculados com 100 ? 1 de suspensão bacteriana, após ferimento com auxilio de ponteira estéril, em ângulo de $45^{\circ}$ e à profundidade de $2 \mathrm{~cm}$. Após a inoculação das respectivas bactérias serem introduzidas no orifício, os mesmos foram selados com vaselina (Pomada Rioquímica) para manutenção da umidade. Os tubérculos foram mantidos em estufa (Nova Técnica) por 20, 24, 48, 72 e 96 h em temperaturas ótimas de desenvolvimento bacteriano: para Pca estabeleceu-se a temperatura de $22{ }^{\circ} \mathrm{C}$, para Pcc de $28^{\circ} \mathrm{C} \mathrm{e}$ para Pch de $35^{\circ} \mathrm{C}$.

A podridão foi estimada por perda de massa após a remoção do tecido macerado com auxílio de palitos de dente e posterior limpeza da área afetada com hastes flexíveis de pontas revestidas com algodão. Os dados obtidos foram transformados em proporção. Em todos as cultivares/bactérias testadas foram usados lotes com cinco tubérculos para cada período de tempo indicado. $\mathrm{O}$ delineamento experimental constou de esquema fatorial com quatro cultivares, três bactérias e quatro repetições, arranjadas em blocos inteiramente casualizados. Os resultados obtidos foram integralizados como área abaixo da curva de progresso da doença (AACPD), por meio da fórmula AACPD $=? ?\left(y_{1}+y_{2}\right) / 2 ? \times\left(t_{2}-t_{1}\right)$, onde $y_{1}$ e $y_{2}$ referem-se a duas avaliações sucessivas da proporção de tecido macerado realizadas nos tempos $t_{1}$ e $t_{2}$, respectivamente. A análise de variância foi realizada pelo pacote estatístico disponível no programa SAS, versão 6.12 para ambiente Windows, com posterior comparação de médias dos tratamentos, através do teste de Tukey, a 0,05 de probabilidade.

\section{RESULTADOS E DISCUSSÃO}

Na avaliação do estado sanitário dos tubérculos, as 
Reação de cultivares de batata à podridão mole causada...

características culturais das colônias permitiram selecionar 13 isolados. Quando realizados os testes bioquímicos e fisiológicos para determinação do gênero dos 13 isolados, nove (1, 4, $5,6,8,9,10,11$ e 13) foram identificados como pertencentes ao gênero Pectobacterium (Tabela 1). Assim, pode-se afirmar que todas as cultivares testadas (Achat, Asterix, Baronesa e Monalisa) possuíam bactérias incitantes de podridão mole. Ressalta-se que os tubérculos-semente são preocupante fonte de contaminação durante o desenvolvimento da cultura e de disseminação desses patógenos para a progênie (De Boer et al., 1978). Dessa forma, até mesmo tubérculos de origem conhecida podem estar infestados. Nesse caso, sugere-se que, nas áreas de origem destes tubérculos, adote-se, no mínimo, três anos de rotação com gramíneas para conseqüente diminuição do inóculo inicial (Lopes \& Buso, 1999).

Nas avaliações executadas para análise da reação das cultivares à podridão mole (Figura 1), o aumento da AACPD dos tubérculos infetados variou consideravelmente. Observase menor suscetibilidade da cultivar Asterix à Pca, em relação às demais cultivares (Figura 1), considerando a temperatura ótima de desenvolvimento bacteriano para essa subespécie (22 ${ }^{\circ} \mathrm{C}$ ). Para a subespécie Pcc, à temperatura de $28{ }^{\circ} \mathrm{C}$, o comportamento da cultivar Asterix apenas tendeu a menor suscetibilidade, pois a AACPD deferiu, estatisticamente, apenas da cultivar Achat. E, para a subespécie Pch, na temperatura de 35 ${ }^{\circ} \mathrm{C}$, a cultivar Asterix apresentou comportamento similar ao da cultivar Baronesa, porém com menor suscetibilidade às demais cultivares Achat e Monalisa.

A $35^{\circ} \mathrm{C}$, temperatura usada para o desenvolvimento da bactéria Pch, a AACPD produzida pelas cultivares impressiona pelo índice atingido. A cultivar Monalisa destaca-se como o mais suscetível, diferindo estatisticamente das demais cultivares.

As bactérias Pca e Pcc apresentaram a menor AACPD em praticamente todas as cultivares, diferindo entre si somente na cultivar Baronesa, em que a área de maceração provocada por Pcc foi maior do que a por Pca. A subespécie Pch induziu maior dano aos tubérculos, diferindo significativamente em todas as cultivares avaliadas, quando comparada às subespécies Pca e Pcc. Os dados, para esse caso, sugerem menor suscetibilidade relativa da cultivar Asterix às bactérias estudadas.

Van der Plank (1975) sugeriu que genes de resistência específica e genes de resistência geral diferem mutuamente, e não existe resistência vertical conhecida de batata para bactérias elicitadoras de podridão mole. Toda variação de resistência de cultivares de batata origina-se de genes de resistência horizontal (Van der Plank, 1978).

A variabilidade na suscetibilidade de cultivares de batata para a incidência de bactérias pectolíticas é relatada em trabalhos de outros pesquisadores (Bains et al., 1999; Reeves et al., 1999). Ibrahim et al. (1978) afirmam que a suscetibilidade à podridão causada por bactérias pectolíticas depende da concentração do inóculo, da temperatura, da cultivar, da idade fisiológica do tubérculo e do intervalo entre a lesão e a inoculação. A aplicação de cálcio em solos de baixa concentração desse elemento e a conseqüente elevação deste nos tubérculos, aumentam a resistência à podridão em virtude da formação do complexo cálcio-pectina, tornando-os mais resistentes à ação das enzimas pectolíticas (Tzeng et al., 1990; Conway et al., 1994; Walters \& Collins, 1995). Outros estudos evidenciam o complexo de polímeros cutina, lignina e suberina da parede celular como limitadores físicos, e os compostos fenólicos e, ainda, os salicilatos e as fitoalexinas como limitadores à multiplicação bacteriana nos tubérculos, substâncias estas produzidas na presença de oxigênio, as quais são tóxicas à bactéria e dificultam a ação das enzimas secretadas pelas pectobactérias, costituindose em fatores envolvidos na resistência de tubérculos à podridão mole (Lyon, 1989). Convém salientar que as pectobactérias crescem melhor sob condições aeróbicas do que anaerobi-

TABELA 1 - Testes bioquímicos e fisiológicos de isolados bacterianos para seleção daqueles pertencentes ao gênero Pectobacterium com cultivares de batata (Solanum tuberosum), de acordo com Robbs (1981) e Schaad (2001)

\begin{tabular}{|c|c|c|c|c|c|c|}
\hline \multirow{2}{*}{ Cultivar } & \multicolumn{6}{|c|}{ Teste bioquímico e fisiológico } \\
\hline & Isolado & Patogenesidade $^{1}$ & Gram & Oxidase & Catalase & $\mathbf{O} / \mathbf{F}^{2}$ \\
\hline \multirow[t]{3}{*}{ Achat } & 1) A 1 & + & - & - & + & $+/+$ \\
\hline & 2) A $3-1$ & - & + & + & + & $+/-$ \\
\hline & 3) A $3-2$ & - & + & - & + & $+/-$ \\
\hline \multirow[t]{4}{*}{ Asterix } & 4) Ast 1 & + & - & - & + & $+/+$ \\
\hline & 5) Ast 1-2 & + & - & - & + & $+/+$ \\
\hline & 6) Ast 2-2 & + & - & - & + & $+/+$ \\
\hline & 7) Ast 3 & - & + & - & + & $+/-$ \\
\hline \multirow[t]{2}{*}{ Baronesa } & 8) B 2 & + & - & - & + & $+/+$ \\
\hline & 9) B 4 & + & - & - & + & $+/+$ \\
\hline \multirow[t]{4}{*}{ Monalisa } & 10) M 1 & + & - & - & + & $+/+$ \\
\hline & 11) $\mathrm{M} 3-1$ & + & - & - & + & $+/+$ \\
\hline & 12) M 3-2 & - & - & + & + & $+/-$ \\
\hline & 13) M 4 & + & - & - & + & $+/+$ \\
\hline
\end{tabular}

${ }^{1}$ Patogenicidade em frutos de pimentão verde

${ }^{2}$ Oxidação/Fermentação 
A.I.H. Benelli et al.

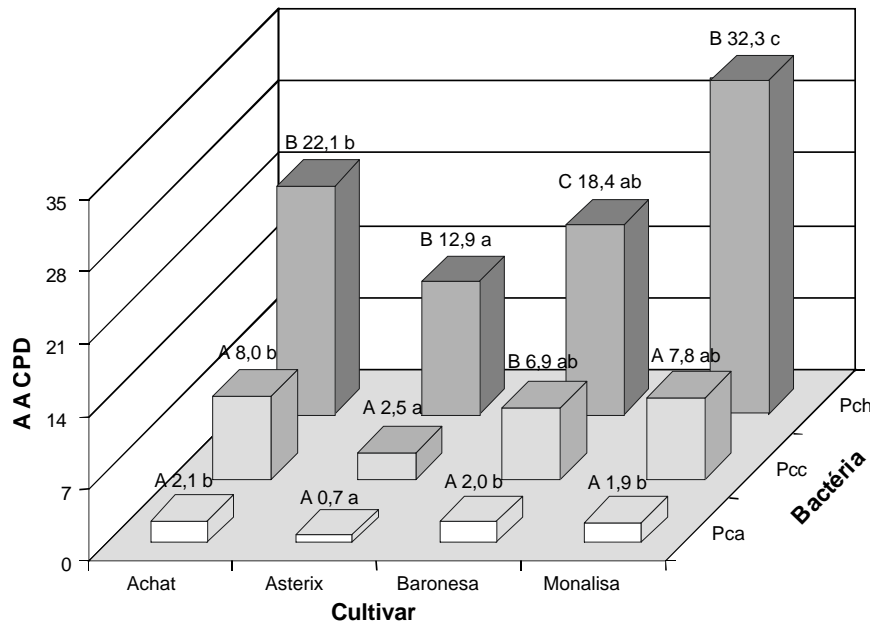

FIG. 1 - Área abaixo da curva de progresso da doença (AACPD) dos cultivares de batata (Solaum tuberosum) infetados com Pectobacterium carotovorum subsp. atrosepticum (Pca), com $P$. carotovorum subsp. carotovorum (Pcc) e com P. chrysanthemi (Pch), causadoras de podridão mole em tubérculos de batata. Médias antecedidas por letras maiúsculas comparam as bactérias e médias seguidas por letras minúsculas comparam os cultivares. Letras iguais não diferem entre si, pelo teste de Tukey, a $\mathrm{P}=0,05$.

camente (Wells, 1974; Meneley \& Stanghellini, 1975). Contudo, segundo De Boer \& Kelman (1978) o aumento de podridão, sob condições anaeróbicas, pode ser atribuído à redução da resistência do tubérculo à doença, devido a baixa concentração de oxigênio no ambiente, e não à variação do metabolismo microbiano. Possivelmente, essa é a justificativa para as elevadas perdas de tubérculos por podridão mole quando as condições de armazenamento não são controladas.

A estimativa de perda de massa dos tubérculos após a remoção do tecido macerado, nos períodos de 20, 24, 48, 72 e $96 \mathrm{~h}$, transformada em proporção e integralizada em AACPD, para a avaliação de maior ou menor suscetibilidade de cultivares neste estudo, mostrou-se uma eficiente forma de medida, podendo ser utilizada como indicador da suscetibilidade de tubérculos à podridão mole causada por pectobactérias.

\section{REFERÊNCIAS BIBLIOGRÁFICAS}

BAINS, P.S., BISHT, V.S., LYNCH, D.R., KAWCHUK, L.M. \& HELGESON, J.P. Identification of stem soft rot (Erwinia carotovora subsp. atroseptica) resistance in potato. American Journal of Potato Research 76:137-141. 1999.

BISOGNIN, D.A. Recomendações técnicas para o cultivo da batata no Rio Grande do Sul e Santa Catarina. Santa Maria - RS: Gráfica Universitária, 1996.

CAPPAERT, M.R., POWELSON, M.L., FRANC, G.D. \& HARRISON, M.D. Irrigation water as a source of inoculum of soft rot erwinias for aerial stem rot of potatoes. Phytopathology 78:16681672. 1988

CONWAY, W.S., SAMS, C.E. \& KELMAN, A. Enhancing the natural resistance of plant tissues to postharvest diseases through calcium applications. Hortscience 29:751-754. 1994.

DENARDIN, N.D. \& FREIRE, J.R.J. Assessment of polymers for the formulation of legume inoculants. World Journal of Microbiology \& Biotechnology 16:215-217. 2000.

DE BOER, S.H., CUPPELS, D.A. \& KELMAN, A. Pectolytic Erwinia spp. in the root zone of potato plants in relation to infestation of daughter tubers. Phytopathology 68:1784-1790. 1978.

DE BOER, S.H. \& KELMAN, A. Influence of oxygen concentration and storage factors on susceptibility of potato tubers to bacterial soft rot (Erwinia carotovora). Potato Research 21:65-80. 1978.

DE BOER, S.H., VERDONK, L. \& VRUGGINK, H. Serological and biochemical variation among potato strains of Erwinia carotovora subsp. atroseptica and their taxonomic relationship to other $E$. carotovora strains. Journal of Applied Bacteriology 63:487-495. 1987.

ELPHISTONE, J.G. La pudrición blanca y la pierna negra de la papa Erwinia spp. Lima: CIP. Boletin de Información Técnica, n.21. 1987.

HAUBEN, L., MOORE, E.R., VAUTERIN, L., STEENACKERS, M., MEGAERT, J., VERDONCK, L. \& SWINGS, J. Phylogenetic position of phytopathogens within the Enterobacteriaceae. Syst. Appl. Microbiol. 21:384-397. 1998.

IBRAHIM, M., JOUAN, R., SAMSON, R., POUTIER, F. \& SAILLY, M. Prospects of pathogenicity test concerning Erwinia carotovora var. carotovora and Erwinia carotovora var. atroseptica, on half potato tubers, variation according to variety of bacterial species and strains, inoculum dose, temperature, variety of potatoes, physiological age of tubers and delay between injury and inoculation. Proceedings, 4th International Conference on Plant Pathogenic Bacteria. Angers França: INRA. 1978. pp.591-602.

KADO, C.J. \& HESKETT, M.G. Selective media for isolation of Agrobacterium, Corynebacterium, Erwinia, Pseudomonas and Xanthomonas. Phytopathology 60:969-976. 1970.

LAPWOOD, D.H. \& GANS, P.T. A method for assessing the field susceptibility of potato cultivars to blackleg (Erwinia carotovora subsp. atroseptica). Annals of Applied Biology 104:315-320. 1984.

LAPWOOD, D.H., READ, P.J. \& SPOKES, J. Methods from assessing the susceptibility of potato tubers of different cultivars to rotting by Erwinia carotovora subsp. carotovora and atroseptica. Plant Pathology 33:13-20. 1984.

LEILLIOT, R.A. \& STEAD, D.E. Methods for the diagnosis of bacterial plant disease. Oxford: BlakwellSientific Publication. 1987.

LOPES, C.A. \& BUSO, J.A . A cultura da batata. Brasília: Embrapa Comunicação para Transferência de Tecnologia, 1999.

LYON, G.D. The biochemical basis of resistance of potatoes to soft rot Erwinia spp. - a review. Plant Pathology 38:313-339. 1989.

MENELEY, J.C. \& STANGHELLINI, M.E. Establishment of an inactive population of Erwinia carotovora in healthy cucumber fruit. Phytopathology 65:670-673. 1975.

OLIVEIRA, A.M.R. Incidência e variabilidade genética de erwinias pectolíticas associadas à canela preta em lavouras de batata no Estado do Rio Grande do Sul. Porto Alegre. (Tese Doutorado em Fitotecnia), Porto Alegre. Universidade Federal do Rio Grande do Sul. 2001.

PÉROMBELON, M.C.M. \& KELMAN, A. Blackleg and other potato diseases caused by soft rot erwinias: proposal for revision of terminology. Plant Disease 71:283-285. 1987.

PÉROMBELON, M.C.M., LOPEZ, M.M., CARBONELL, J. \& HYMAN, L.J. Effects of contamination by Erwinia carotovora subsp. 
Reação de cultivares de batata à podridão mole causada...

carotovora and E. carotovora subsp. atroseptica of potato seed tubers and of cultivar resistance on blanking or non-emergence and blackleg development in Valencia, Spain. Potato Research 31:591-599. 1988.

REEVES, A.F., OLANYA, O.M., HUNTER, J.H. \& WELLS, J.M. Evaluation of potato varieties and selections for resistance to bacterial soft rot. American Journal of Potato Research 74:183-189. 1999.

ROBBS, C.F. Taxonomia, bioecologia e principais representantes do gênero Erwinia no Brasil. Fitopatologia Brasileira 6:304-305. 1981.

SCHAAD, N.W., JONES, J.B. \& CHUN, W. Laboratory guide for identification of plant pathogenic bacteria. 3 ed. St. Paul: APS Press 2001.

SIDRA-SISTEMA IBGE DE RECUPERAÇÃO AUTOMÁTICA. Banco de dados agregados. Disponível na Internet. http:// sidra.ibge.gov.br/bda. 30 nov. 2001.

TUMELERO, A.I. \& DENARDIN, N.D. Formulação para preservação de bactérias fitopatogênicas. Fitopatologia Brasileira 26:286. 2001 (Resumo).
TZENG, K.C., MC GUIRE, R.G. \& KELMAN, A. Resistance of tubers from different potato cultivars to soft rot caused by Erwinia carotovora subs. atroseptica. American Potato Journal 67:287-305. 1990.

VAN DER PLANK, J.E. Principles of plant infection. New York: Academic Press. 1975.

VAN DER PLANK, J.E. Genetic and molecular basis of plant pathogenesis. Berlin: Springer-Verlag. 1978.

WASTIE, R.L., JELLIS, G.J., LAPWOOD, D.H., LOGAN, C., LITTLE, G. \& PHILIPS, M.S. Assessing potato cultivars for resistance to tuber soft rot (Erwinia carotovora subsp. atroseptica) at four test centers in the U.K. Potato Research 31:67-72. 1988.

WELLS, J.M. Growth of Erwinia carotovora, E. atroseptica and Pseudomonas fluorescens in low oxygen and high carbon dioxide atmospheres. Phytopathology 64:1012-1015. 1974.

WALTERS, P.I.C. \& COLLINS, W.W. Estimation of genetic parameters for resistance to Erwinia soft rot, specific gravity, and calcium concentration in diploid potatoes. Crop Science 35:1346-1352. 1995. 